\title{
Smart and Strategic Procurement, Use and Maintenance Partnerships in Engineering Equipment for Sustainable Development and Training in Sub- Saharan Africa using a Systems Thinking Approach
}

\author{
Wilson R. Nyemba ${ }^{1}$, and Charles Mbohwa ${ }^{2}$ \\ ${ }^{1}$ Department of Mechanical Engineering Science, Faculty of Engineering \& the Built Environment, \\ University of Johannesburg, Auckland Park 2006, Johannesburg, South Africa \\ nyemba@yahoo.com \\ ${ }^{2}$ Professor of Sustainability Engineering, Department of Quality and Operations Management \& Vice \\ Dean for Research and Innovation, Faculty of Engineering and the Built Environment, University of \\ Johannesburg, Auckland Park 2006, Johannesburg, South Africa \\ cmbohwa@uj.ac.za
}

\begin{abstract}
Most engineering institutions in Sub-Saharan Africa generally suffer from the persistent shortage and lack of accessibility to modern engineering equipment for the training of engineers. The old and obsolete equipment available, invariably pose challenges on the caliber of engineers being churned out to run industries in these developing countries. Based on research carried out at four engineering institutions in Sub-Saharan Africa through data collection and analysis, a smart procurement, use and maintenance strategy in the form of strategic partnerships with industry was formulated using a systems thinking approach. This paper looks at the development of this strategy and how the proposed partnerships can help in sustainable development, capacity building and ultimately bridging the gap between industry and academia. The implementation of this novel approach at the University of Zimbabwe has brought immense benefits such as students and staff access to modern equipment and technology.
\end{abstract}

Keywords: Capacity building, engineering equipment, maintenance, procurement, smart partnerships, sustainability.

\section{Introduction}

Research initiated by the Network of Users of Scientific Equipment in Eastern and Southern Africa (NUSESA) was carried out at four engineering institutions, namely University of Zimbabwe (UZ), University of Dar es Salaam (UDSM), Makerere University (MU) and Universidade Eduardo Mondlane (UEM) in 2005, to establish the status, use and maintenance procedures and ultimately to foster a culture of preventive maintenance to enhance and prolong the life of such equipment [1]. The initiative was prompted by a previous study which revealed that, research output at engineering institutions in Sub-Saharan Africa may have been seriously affected by laboratory equipment challenges, hence the need for long term strategies for sustainable development through the improvement of acquisition, use and maintenance, enhanced capacity building and sustainability and collaborative research, training and exchange of staff among the regional faculties of engineering [2].

ACRID 2017, June 20-21, Victoria Falls, Zimbabwe

Copyright (C) 2017

DOI 10.4108/eai.20-6-2017.2270631 
Laboratory equipment and staff for most engineering faculties in Sub-Saharan Africa were provided as part of the agreements that led to the establishments of these institutions as colleges of universities mostly from Europe. With time, these colleges were weaned off to run as standalone institutions while the expatriate staff gradually returned to their home countries [3]. Unfortunately, in a majority of cases, no sustainability plans were left in place to ensure continuity, leading to deterioration, obsolescence and in some cases underutilization due to lack of expertise [1]. This was compounded by recession in the region during the period 20002010, which forced some of the trained personnel to flee the region for greener pastures abroad [5]. This was partly the reason for the establishment of NUSESA to address these common challenges as a regional bloc, supported by the Swedish International Development Cooperation Agency (Sida) [4].

Since the installation of the laboratory equipment, there has been little or no replenishments because of limited financial capacity as the faculties rely on university grants that come from scarce government resources. The research also revealed that the bulk of equipment is over 15 years. Although some of the equipment is still functional, the technology is outdated, resulting in producing graduates who may be qualified but are unemployable. The conventional equipment such as the analog pneumatic and process control simulator shown in Fig. 1(a), which was installed in Mechanical Engineering at UZ in 1976 is no longer appropriate for producing the relevant skills that industry needs apart from the fact that the supplier, TecQuipment no longer supports this type of equipment. Due to limited capacities, the institutions are sometimes forced to absorb more students than they can ordinarily handle, resulting in overcrowding around the few machines available such as shown in Fig. (1b).

The absence of formal links and collaborations between industry and academia creates a costly vacuum in that prospective employers end up offering training beyond what they would have done had there been adequate grounding before graduation [5]. Most of these challenges can demotivate academics and students who advertently may lose interest or develop a fear for working with machines. This research was therefore aimed at utilizing the data availed from the NUSESA reports to develop a strategy to address these challenges and in the process improve procurement while enhancing capacity building and sustainability in the training of engineers. The development of the strategy was modelled using a holistic systems thinking approach that encompassed all stakeholders such as similar institutions locally and regionally as well as the creation of formal links between industry and academia thereby bridging the gap between them and filling the void.

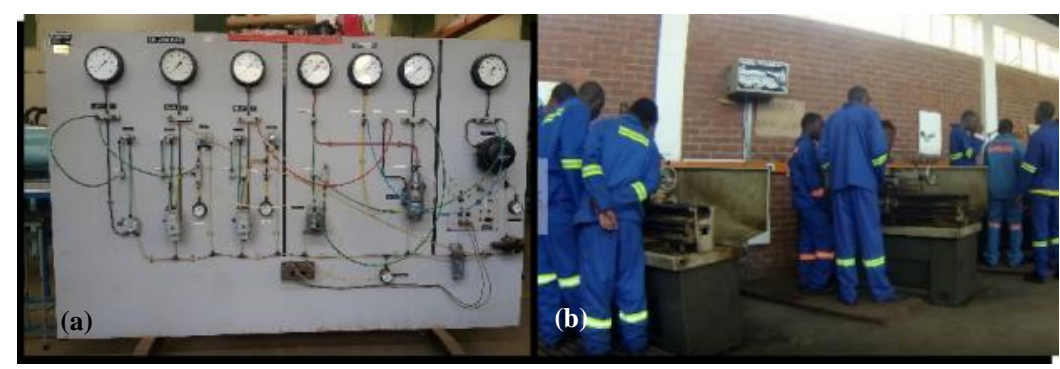

Fig. 1. (a) Analog and conventional equipment and (b) Insufficient machine tools 


\section{Background and literature review}

In recent years, technology has been changing at a much faster pace than it did a few years ago. This trend has resulted in Original Equipment Manufacturers (OEMs) modifying engineering equipment and in some cases completely changing the machines and the technologies that drive them [6]. Although global competition also forced the OEMs to reduce their costs in order to remain profitable, the cost of new equipment remains unaffordable to institutions in the developing world [7]. Changes in the machines and the technologies that drive them, create other challenges such as cost and complexity. OEMs are largely domiciled in developed countries which have the capacity to deal with issues of rapid changes in technology. While the use of microchips has reduced the sizes of equipment in general and improved the way machines are driven, the complexity introduced requires continuous professional development and training of operators, a costly requirement [8]. In most cases, expertise to train these can only be found at the OEMs. In addition, the maintenance and at times, the required regular calibration becomes more problematic compared to conventional machines [9].

A considerable number of the machine tools in these engineering institutions were acquired through the support of development aid organizations such as the British Overseas Development Authority (ODA) in the case of UZ, MU and UDSM as well as the Organization for Economic Cooperation and Development (OECD) from Portugal in the case of UEM [3, 10]. Unfortunately aid organizations provided the initial support to purchase the equipment while funds for maintenance and upkeep were expected to be borne by the recipient institutions [11]. Due to limited financial capacities, the institutions faced difficulties in sourcing funds to maintain the equipment, resulting in reduced life spans. In recent years, this challenge prompted aid organizations to demand sustainability plans before donations and some of the institutions failed on this account. The need to maintain equipment properly is more of a necessity nowadays than it was a few years ago and thus researchers and practitioners have been placing emphasis and attention on maintenance, not only to ensure longer life spans for their equipment but also in anticipation of further aid from donors [12].

The major challenges in procurement, use and maintenance of equipment in these regional institutions are either administrative, i.e. lack of policies, guidelines and funding or technical, i.e. lack of expertise and preventive maintenance schedules [13]. Engineering institutions are mandated with the development of human resources required to run engineering firms in all spheres and disciplines such as designs, constructions, processing, manufacturing and provision of water and power. There is a need for academia to formulate university education in line with the needs for industry in order to remain relevant in view of the rapid changes in technology and industrial systems [14]. Technical education systems also need to be revamped and kept in tandem with the changes while students are equipped with relevant skills to prepare them fully for industry [15]. Such practices as student and staff attachments, have been applied successfully in the developed world where lecturers with no industrial experience are seconded to industry to enhance their skills as well as familiarize with current industrial needs and available equipment [16]. Apart from sharpening the lecturers' practical skills through real problem solving, communication and inculcating a research and development culture in industry, the attachment programs also strengthen links between industry and academia thereby helping to bridge the gap between the two.

The four institutions relied heavily on foreign aid in order to equip their laboratories and to date this trend continues albeit at a lower scale. Most of the development aid agencies are controlled by their national governments and as such this is finite and unsustainable. Dealing 
with and interacting with donors has proved that while the support has benefited the institutions, there are usually no strings attached to make the donations continue over longer periods of time, hence the unpredictable nature of foreign aid. Investing in engineering skills and competences and promoting collaborations among regional institutions as well as strengthening links between academia and industry can help in self-sustenance and reducing foreign aid dependency [17]. There is therefore a need to develop sustainable systems that meet the needs of the present without compromising the ability of future generations to meet their own needs [18], thus, the capacity to withstand any setbacks that may arise in the use and maintenance of the equipment. In view of the unpredictable nature of foreign aid, this paper focuses on and answers questions revolving around what engineering institutions in SubSaharan Africa can do to bridge the gap between industry and academia in order to improve access to modern equipment and technology as well as developing sustainable strategies in procurement, use and maintenance of such equipment.

\section{Research methodology}

The general framework of the research was formulated through a series of meetings by representatives of the four institutions after which each institution was tasked to establish the status of laboratory equipment in their faculties. This paper focusses on and uses the results obtained from the UZ with occasional reference to the other three institutions. Principal investigators were the chief technicians of the departments.

\subsection{Data collection}

Table 1 shows the form that was designed for data collection based on what the faculties agreed. Where necessary, guidelines and keys were provided on how to record the data. The aim was to establish how the equipment was acquired, installed and commissioned. The state of each piece of equipment in terms of its condition, functionality and use were also recorded. The equipment maintenance schedules were expanded to include frequency of servicing, expertise (local or foreign), availability of manuals, costs and sources of funding.

Table 1.Data collection form

\begin{tabular}{|c|c|c|c|c|c|c|c|c|c|c|c|}
\hline \multicolumn{12}{|c|}{ University of Zimbabwe: NUSESA Equipment Maintenance Details } \\
\hline \multicolumn{12}{|c|}{$\begin{array}{l}\text { Department: } \ldots \ldots \ldots \ldots \ldots \ldots \ldots \ldots \ldots \ldots \ldots \text { Date Completed: } \\
\ldots \ldots \ldots \ldots \ldots \ldots\end{array}$} \\
\hline 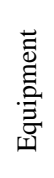 & 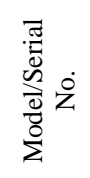 & 离 & 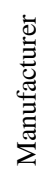 & 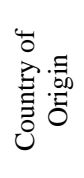 & 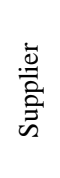 & $\sum_{\substack{0 \\
0}}^{0}$ & 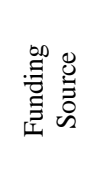 & 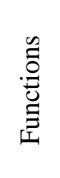 & 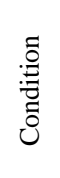 & 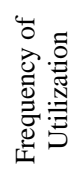 & 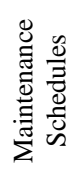 \\
\hline
\end{tabular}




\subsection{Maintenance experts survey}

Table 1 shows the form that was designed for data collection based on what the faculties agreed. Where necessary, guidelines and keys were provided on how to record the data. The aim was to establish how the equipment was acquired, installed and commissioned. The state of each piece of equipment in terms of its condition, functionality and use were also recorded. The equipment maintenance schedules were expanded to include frequency of servicing, expertise (local or foreign), availability of manuals, costs and sources of funding.

\subsection{Consolidation and analysis of data}

The collected data from equipment details and the maintenance experts' survey was consolidated in a uniform format in preparation for the local stakeholders' workshop and the final report to NUSESA as well authorities at UZ. In addition, a pairwise analysis of factors drawn from the collected data was done to derive inferences such as age and condition, in descriptive form followed by statistical analysis.

\subsection{Stakeholders workshop}

A stakeholders' workshop comprising all users of equipment in the departments, as well as engineers from industry using similar equipment, was held to synthesize the information. Apart from discussing the preliminary findings, it was also an opportunity to provide additional information in order to maintain some uniformity in the final report and recommendations to NUSESA and university authorities. The workshop was split into three main thematic groups that were tasked to look into Maintenance Policy, Capacity Building and Training Requirements respectively. Based on the available data from the departments, each of the thematic groups focused on the following; stakeholders to be consulted and involved, critical issues to be addressed, how to enforce or implement recommendations, development of a regional database of equipment and experts, regional collaborations, exchange of staff, sharing of resources, sources of funding, how to improve links and bridge the gap between industry and academia and continuous professional development programs and training of users.

\section{Results}

\subsection{Origins and age of equipment}

The graphs and highlights below are a descriptive interpretation of the aggregated data that came from the six engineering departments at UZ and from the users' questionnaire responses. Most of the equipment in all the departments had surpassed 15 years, a statistic which was worrisome for a technology institution, especially in view of the rapid changes in technology. 


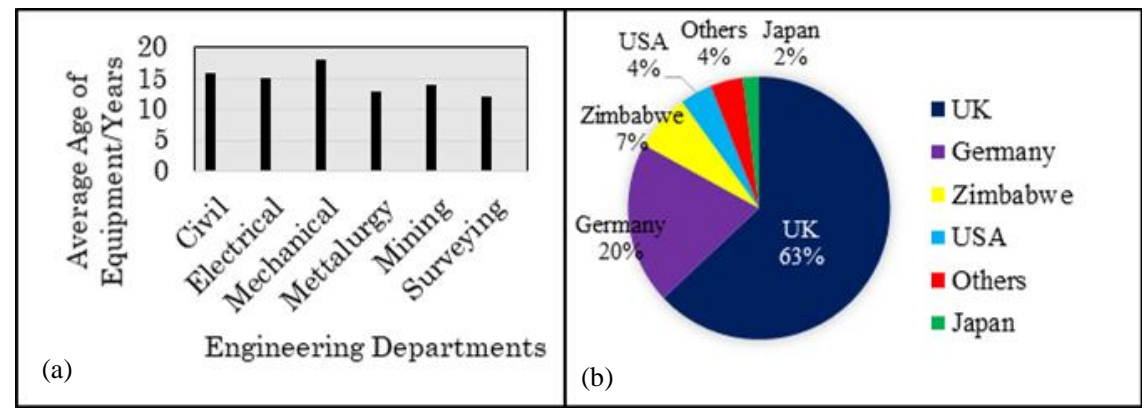

Fig. 2. (a) Average age of equipment and (b) Countries of Origin

$70 \%$ of the equipment, as shown in Fig. 2 (b) originated from the United Kingdom through the British Council and ODA as the faculty was established with the traditional departments of Civil, Electrical and Mechanical as a College of the University of London before it had its own charter [3]. The German Technical Cooperation Agency (GTZ) provided $21 \%$ of the equipment to support the establishment of Mining, Metallurgy and Surveying departments in the mid-1980s. As such, most of the OEMs and suppliers were either from the UK or Germany. The remainder of the equipment came from UNESCO-IHE and notably, the $\mathrm{UZ}$ and the Government of Zimbabwe only provided a combined $7 \%$.

\subsection{Condition and utilisation of the equipment}

A worrisome observation made was the high number of machines that were classified as either obsolete or not working, e.g. $43 \%$ for Surveying shown in Fig. 3(a), an indication reflective of the level of staffing. Equipment classified as functional but not being utilized pointed to the lack of expertise for operating such machines. Fig. 3(b) shows that most of the equipment was used for research and teaching but with a low uptake for consultancies that can generate income for maintenance. This was partly attributed to the young and inexperienced academics within the departments.

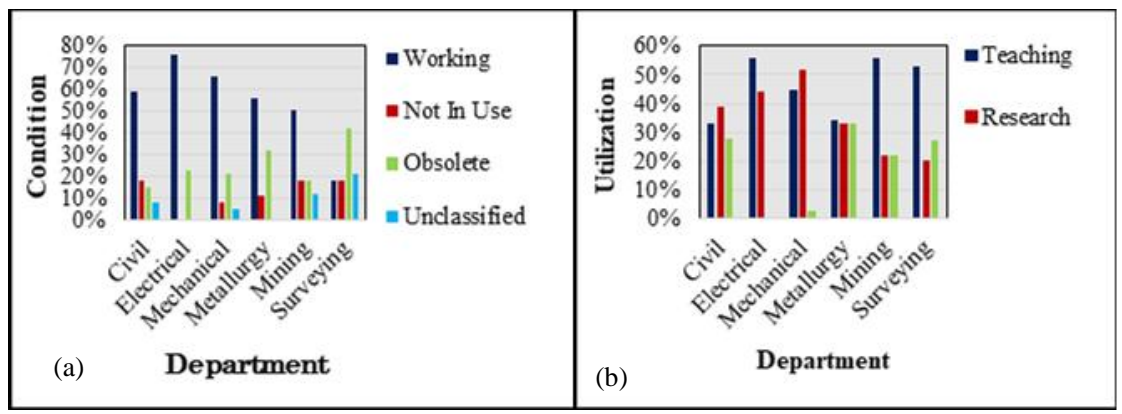

Fig. 3. (a) Condition of equipment and (b) Utilization of equipment 


\subsection{Condition and utilisation of the equipment}

Minimal maintenance schedules were kept by the departments who relied mostly on experience and institutional memory in cases where manuals were not available. As shown in Fig. 4(a), equipment maintenance in the 3 traditional departments was carried out by local expertise whereas the other three outsourced their requirements. The available records for maintenance costs were not adequate to provide any meaningful descriptive statistics or analysis since most of the departments operated on breakdown maintenance. However the costs were covered by the university grants. Information derived from the maintenance experts' survey also revealed that the six departments faced common challenges such as; obsolete and outdated equipment, lack of maintenance funds and costly spares that are imported, as shown in Fig. 4(b).

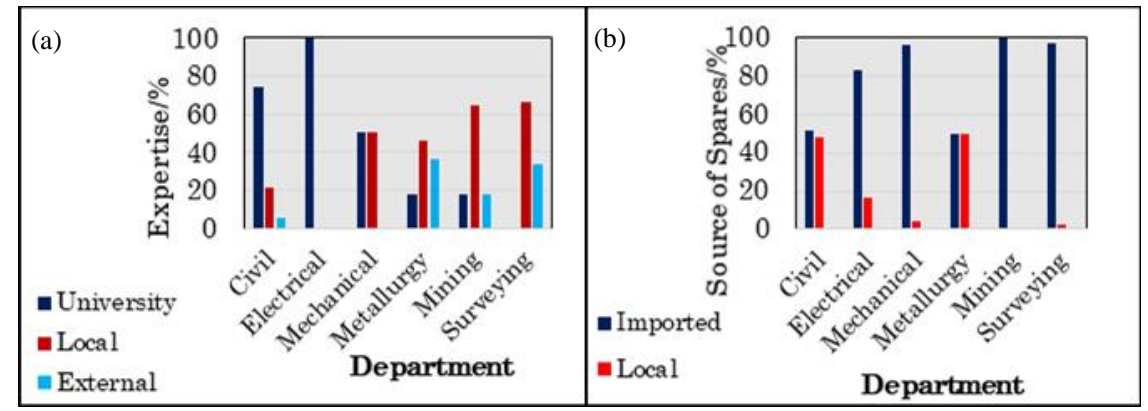

Fig. 4. (a) Maintenance expertise and (b) Sources of spares

\section{Smart procurement, use and maintenance strategy}

Although there were several challenges observed in the research carried out at UZ, the focus of this paper was on how academic institutions can improve access to modern equipment in an affordable and sustainable manner without relying heavily on the finite and unsustainable foreign aid. The challenges observed at UZ were a mirror image of the other institutions, revolving around old and conventional machines, obsolescence, underutilization and lack of collaborations between industry and academia, prompting the evident need to increase and improve links between industry and academia. A systems thinking approach that interconnects direct beneficiaries and stakeholders of higher education training, i.e. academia, industry and government was proposed. The smart procurement, use and maintenance strategy was modelled along the Build-Operate-Transfer (BOT) phenomena which is frequently used in construction projects between the private sector and government $[19,20]$. This was premised on a 'win-win' situation for all stakeholders, wherein academia provides the expertise for research and development in solving industry's problems, industry provides the financial support and access to modern equipment and technology and government facilitates such linkages through appropriate manpower and professional development policies. The proposal is summarized in Fig. 5. Partnership agreements can be made between individual 
institutions and companies or as consortiums while each party focuses on their strengths and core business to save costs.

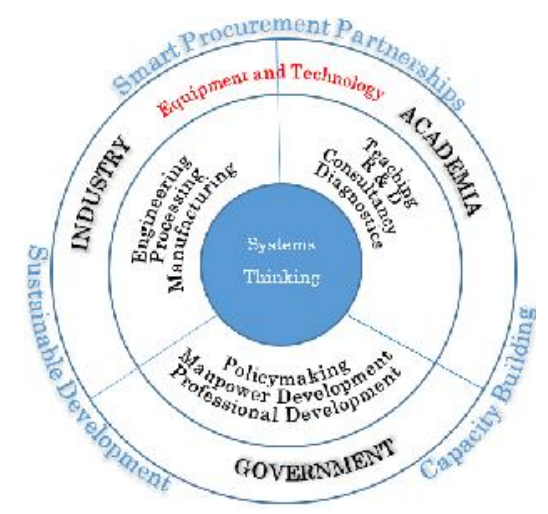

Fig. 5. Systems thinking smart procurement, use and maintenance model

\section{Discussion and recommendations}

The results obtained from the research at UZ were a mirror image of the situations obtaining at the other three Sub-Saharan Africa engineering institutions which participated in the NUSESA initiated and funded project. Chief among the challenges observed were; lack of access to modern engineering equipment, no formal links between industry and academia, obsolescence and underutilization. Most of the equipment still in use was provided by aid agencies over 15 years ago and as such OEMs are no longer able to support the old technology. There were no observable and distinct patterns between the conditions of equipment and their functions, an indication that the challenges were not as a result of misuse but lack of knowledge and training, hence the underutilization noted. The absence of operational manuals and scheduled maintenance procedures also contributed to the deterioration of equipment, prompting the need for continuous professional development for operators. Limitations in funding for maintenance meant that some of the equipment were left to run for long periods without maintenance, leading to reduced life spans.

Among the recommendations made to build capacity and self-sustenance were that maintenance policies that spell out scheduled and preventive routines must be implemented to improve the life spans of equipment. Industry is a key stakeholder in the training of engineering students and thus should play a key role in ensuring that students and staff have access to appropriate and modern engineering equipment through formalized link agreements. Appropriate innovations to solve industry's challenges could also be an avenue to win the needed support from industry. Technicians in academic institutions can also use their skills to produce spare parts for equipment as a way to substitute costly imports. A carefully planned schedule and sharing of duplicate equipment in departments and participating institutions helps in reducing maintenance costs as well as addressing underutilization. Similarly, expertise can also be shared regionally through virtual networks without the need for the 
physical movement of staff, thereby reducing costs and promoting collaborations and joint regional projects and research. Aid organizations are in support of such collaborations and thus it would enhance the chances for financial support.

Based on these recommendations, a smart procurement, use and maintenance strategy was modelled along the lines of public, private partnerships and the BOT phenomena. This has been implemented at the UZ which has realized such benefits as; Professorial Chair in Mining Engineering fully funded by one of the mining companies in Zimbabwe, establishment of a laboratory for telecommunications by the provision of a live GSM base station by a telecommunications company in Zimbabwe, provision of a renewable energy solar trailer by the Austrian Development Cooperation and the Day Ahead Marketing Electricity Trading Platform by the Southern Africa Development Community (SADC) division, Southern African Power Pool (SAPP). More companies in Zimbabwe have embraced the model and are now providing access to their companies for staff and students on secondments and attachments respectively.

\section{Conclusions}

An analysis of different factors and parameters were used to determine underlying patterns in procurement, use and maintenance of equipment used in the training of engineering students at UZ, results of which were a reflection of the patterns at the other three SubSaharan institutions that participated in the NUSESA initiated project funded by Sida. Inferences drawn from this analysis pointed to the need to improve and formalize links between industry and academia in order to improve students and staff access to modern engineering equipment and technology. Using a systems thinking approach that encompassed and promoted the interconnectedness of key stakeholders in academia, industry and government, a smart procurement, use and maintenance strategy was developed and some of the recommendations have been implemented at UZ, realizing benefits such as exposure to modern practices, equipment and systems by academics and appropriate research and development projects carried out for industry, ultimately reducing the gap between industry and academia.

Acknowledgments. The authors would like to acknowledge the input by lecturers and technicians at UZ, engineers from the local industry, colleagues from UDSM, MU and UEM and the financial support provided by Sida through NUSESA.

\section{References}

[1] Nyemba, W.R., Mashamba, A., Mbohwa, C.: Equipment maintenance challenges and solutions for capacity building and sustainability in the training of engineers: the case for the University of Zimbabwe. In: 1st International Conference on Sustainable Materials Processing and Manufacturing, Vol. 7, pp. 303-308 (2017)

[2] Mwamila, B.L.M., Thulstrup, E.W., (eds.): Engineering and Technology for Sustainable Development - Research, Education and Development - Proceedings of a Regional Meeting held in Bagamoyo, Tanzania, University of Dar es Salaam (2002)

[3] Zinyemba, R., (ed.): Academia and the Dynamics of Transformative Leadership: The Experience of the University of Zimbabwe in the First Decade after Zimbabwe's Independence (1981-1992), University of Zimbabwe Publications (2010) 
[4] Lindgren, E.S.: Sida's Support to Network of Users of Scientific Equipment in Eastern and Southern Africa (NUSESA), Final Evaluation Report, Sida (2001), Available: http://www.sida.se/evaluation/

[5] World Bank: Reform and Regional Integration of Professional Services in East Africa: Time for Action, World Bank Report No. 57672-AFR, World Bank (2010), Available: http://siteresources.worldbank.org/INTAFRREGTOPTRADE/Resources/NEWReformProfessionaSer vicesEAC Report.pdf

[6] Martinez, V., Bastl, M., Kingston, J., Evans S.: Challenges in transforming manufacturing organizations into product-service providers, Journal of Manufacturing Technology Management, Vol. 21 Issue 4, pp. 449-469 (2010)

[7] Allais, R., Gobert, J.: A multidisciplinary method for sustainability assessment of PSS: Challenges and developments, CIRP Journal of Manufacturing Science and Technology, Vol. 15), pp. 56-64 (2016)

[8] Ahuja, I.P.S., Khamba, J.S.: Strategies and success factors for overcoming challenges in TPM implementation in Indian manufacturing industry, Journal of Quality in Maintenance Engineering, Vol. 14 Issue 2, pp. 123-147 (2008)

[9] Ju, H.: Design a training and maintenance system based on code identification, IERI Procedia, Vol. 1, pp. 155-159 (2012)

[10] Macauhub, Mozambique is 2nd largest recipient of public aid from Portugal, (2013), Available: http://www.macauhub.com.mo/en/2013/01/17/mozambique-is-2nd-largest-recipient-of-public-aidfrom-portugal/

[11] Donarski, J., Heath, R.W., Wallace, J.B.: Training through consultancy to improve maintenance management, Journal of European Industrial Training, Vol. 7 Issue 3, pp. 10-16 (1983)

[12] Parida, A., Kumar, U.: Maintenance performance measurement (MPM): issues and challenges, Journal of Quality in Maintenance Engineering, Vol. 12 Issue 3, pp. 239-251 (2006)

[13] Mzengeza, D.: Maintenance of Equipment, in: Mwamila, B.L.M., Thulstrup, E.W., (eds.): Engineering and Technology for Sustainable Development - Research, Education and Development Proceedings of a Regional Meeting held in Bagamoyo, Tanzania, University of Dar es Salaam (2002) [14] Abdullah, M.F.A., Alias A.J.: University-Industry Smart Partnership in Enhancing Aviation Technology Education, Proceedings of the 2005 Regional Conference on Engineering Education, pp. 437-439, Centre for Engineering Education, Universiti Teknologi Malaysia (2005) Available: http://tree.utm.my/wp-content/uploads/2013/02/PRT-Mohd-Fakhrulrazi-A-Abdullah-Ahmad-JaisAlias_ok.pdf

[15] Ahmad M.F.B.: Lecturers' Industrial Attachment Programme to increase Lecturers' Soft Skill and Technological Competencies for Global Stability and Security, Journal of Sustainable Development, Vol. 4 Issue 1, pp. 281-283 (2011)

[16] Universiti Malaysia Sabah, School of Engineering Information Technology: Industrial Attachment Programme for Lecturers, Implementation Manual, (2010), Available: http://sktm.ums.edu.my/sktm/files/20111131214540.Manual\%20Pelaksanaan\%20PLIP\%20 (2011).pdf?file_id=34

[17] Nyemba W.R.: Engineering Skills are the key to achieving Sustainable Development and reducing Foreign Aid Dependency, Huffington Post (UK) (2017), Available: http://www.huffingtonpost.co.uk/wilson-nyemba/engineering-skills-are-th_b_14135774.html

[18] Iung, B., Levrat, E.: Advanced maintenance services for promoting sustainability, Procedia CIRP, Vol. 22, pp. 15-22 (2014)

[19] Asao, K., Miyamoto, T., Kato, H., Diaz, C.E.D.: Comparison of revenue guarantee programs in build-operation-transfer projects, Built Environment Project and Asset Management, Vol. 3 Issue 2, pp. 214-227 (2013)

[20] Yang, J.B., Yang, C.C., Kao, C.K.: Evaluating schedule delay causes for private participating public construction works under the Build-Operate-Transfer model, International Journal of Project Management, Vol. 28, pp. 569-579 (2010) 